\title{
AC 2008-2314: THINKING GLOBALLY, ACTING LOCALLY: STRATEGIES FOR IMPROVING INTERNATIONAL EXPERIENCE AND EMPLOYABILITY SKILLS OF UNDERGRADUATE STUDENTS OF VEHICLE ENGINEERING
}

\author{
Annette Casey, Joanneum University of Applied Sciences, Department of Automotive Engineering, \\ Graz, Austria
}

Annette Casey is an English language trainer in the Department of Automotive Engineering, Joanneum University of Applied Sciences. She graduated from Dublin City University with a degree in Applied Languages (Translation and Interpreting) in 1991. She has been teaching business and technical English both in industry and at university level in Austria for the past 12 years.

\section{Emilia Bratschitsch, Joanneum Univeristy of Applied Sciences}

Emilia Bratschitsch is head of the Department of Vehicle Technologies (Automotive and Railway Engineering) and teaches Electrics, Electronics and Methods of Signal Processing at the University of Applied Sciences Joanneum in Graz (Austria). She is also a visiting lecturer at the Faculty of Transport of the Technical University of Sofia (Bulgaria). She graduated with a degree in Medical Electronics as well in Technical Journalism from the Technical University of Sofia and received her $\mathrm{PhD}$ from the Technical University of Graz (Austria). She gained industrial experience in automation of control systems, engineering of electronic control systems and software development. Her R\&D activities comprise design of signal processing and data analysis methods, modelling, simulation and control of automotive systems as well as Engineering Education.

\section{Adrian Millward-Sadler, Joanneum University of Applied Sciences}

Adrian Millward-Sadler is an English language trainer in the Department of Automotive Engineering, at the Joanneum University of Applied Sciences in Graz. He graduated with a joint honours degree in German and Russian languages from the Victoria University of Manchester in 1998 and completed his Masters' degree in European Languages and Culture at the same institution in 2000. Since completing his teaching qualification in the same year, he has taught English variously in Spain, Greece, Prague and Graz both in the private and university sectors, as well as having worked in private language school management. He has been teaching in the department for 3 years with interests in language acquisition and Engineering Education. 


\title{
Thinking globally, acting locally: strategies for improving international experience and employability skills of undergraduate students of vehicle engineering
}

\begin{abstract}
This paper presents the strategies and academic measures in place in an undergraduate vehicle engineering program, which aim to provide students with the experience and skills demanded by the vehicle industry, both global and local.

The demands placed on graduates of engineering programs in the workplace are manifold, regardless of where they work. Companies expect graduates to come equipped with engineering expertise, problem-solving skills, the ability to work alone and in teams, knowledge of business and management practices, as well as communication and interpersonal skills, foreign language proficiency, and some form of international experience. Nowhere is this more prevalent than in the vehicle sector.
\end{abstract}

With this in mind, a compact engineering curriculum was developed in close cooperation with the automotive and railway industry in Austria to meet the needs of the evolving local and international markets. The curriculum, based on a broad palette of engineering subjects, project work, a mandatory internship, business and management training, and English as a second language, is still in place over a decade later, with a number of important additions.

This paper will describe the main features of the curriculum as it is today and show how the implementation of specific academic measures to the degree program has been a vital step towards providing a more all-round educational experience. It also aims to illustrate how, in the absence of a specifically designated 'global engineering program', a greater international dimension can be added to an already compact and demanding engineering program to the benefit of all the students.

\section{Introduction}

In the early nineties, the University of Applied Sciences (UAS) system was in its infancy in Austria. This 'alternative' to the traditional university system was born of the need to fill a gap in the education market - a form of third-level education which would equip students with the specific knowledge, skills and experience sought by different sectors of industry ${ }^{1}$. The vehicle engineering sector had taken a strong foothold in the southeast region of Austria, and the big German OEMs were within easy reach. Thus, the Joanneum University of Applied Sciences ${ }^{2}$ in Graz set about developing a 4-year (8-semester) degree program in Vehicle Technology (Automotive Engineering/Railway Engineering). The development team consisted not only of specialists in the area of engineering and engineering education, but also consultants from industry and representatives of the local government. The idea was to combine traditional mechanical engineering subjects with automotive/railway specific lectures covering up-to-date methods and practices to ensure that the graduates would have a sufficient background to work as professional engineers in their chosen discipline. These engineering subjects should be 
complemented with experiential learning and practical experience, in the form of hands-on laboratory and machine shop practice, an internship (at home or abroad), and one major project in the $6^{\text {th }}$ semester. To round off the program, business and management subjects (including both hard and soft skills) and English as a second language should be included. The result was a challenging engineering curriculum, designed to produce graduates with a high degree of employability and thus satisfy the market's need for highly-qualified engineering personnel.

The response from industry was very good from the start, with the majority of graduates making a seamless transition into engineering positions in internationally renowned companies, many of them based in Austria. This confirmed that the 'recipe' itself was a good one, and that the program was succeeding in what it had set out to do. However, like all good 'recipes', ours would need to be refined in order to provide our students with a competitive advantage in a wider employment market. In a position paper entitled 'Internationalisation at Home' ${ }^{3}$, Bernd Wächter writes that 'in a global economy it makes less sense than ever before to orient the qualifications passed on to students towards the needs of the national labour market'. This is true of the automotive engineering sector in particular. In the past decade or more we have experienced an increasing shift away from traditional centres of development and production in North America and Europe to other parts of the globe. If we as educators are to keep pace with this development, we need to equip our students with the skills to work in a more multinational environment.

As the degree program progressed through its early years, the academic staff in the Department of Vehicle Technology began to look at ways of further enhancing the development of the much sought-after 'employability skills' and increasing international exposure for all undergraduates participating in the program ${ }^{4}$. We identified a number of key areas to be improved and the strategies and/or measures needed to do this:

- Interdisciplinary thinking - by introducing project-based learning (PBL) as an integral part of the junior and sophomore years.

- International experience - by further promoting the value of internships abroad, setting up solid partnerships with foreign universities to encourage study abroad and participating in an international student competition (Formula Student).

- Language skills/Communication skills - by maintaining the existing language program over six of the eight semesters, increasing the number of subject-specific lectures in English to encourage exchange and encouraging the use of English as a real working language.

The following sections describe the curriculum as it is today, including the two specializations, and explain the abovementioned measures and their implementation in more detail.

\section{The curriculum}

The bulk of the program's original curriculum has remained in place for over ten years, starting out in 1996 with Automotive Engineering and going on to include a second specialization in Railway Engineering in $1999^{2}$. The following paragraphs provide a general description of the features of the original curriculum which were maintained. Figure 1 lists the courses, grouped according to semester, which form the current curriculum. 


\section{Vehicle Technology Curriculum}

\section{Semester 1:}

Engineering Mathematics 1

Mechanics 1

Informatics and Programming 1

Introduction to Natural Sciences

Descriptive Geometry

Chemistry

Mechanical Technologies

Filing Processes and Measuring Technologies in Production

Introduction to Automotive Engineering and Transport Systems

Machine Shop 1

Semester 2:

Engineering Mathematics 2

Mechanics 2

Informatics and Programming 2

Strength of Materials 1

Thermodynamics 1

Materials Science

Production Planning and Systems 1

General English 1

Machine Shop 2

Semester 3

Engineering Mathematics 3

Mechanics 3

Informatics and Programming 3

Strength of Materials 2

Thermodynamics 2

Basics of Electrical Engineering

Tool Building and Refining Technologies

Casting, Forging, Hardening, Welding

Business Management 1

Production Planning and Systems 2

General English 2

Semester 4:

Fluid Mechanics

General Electrical Engineering and Electronics

Reciprocal and Internal Combustion Engines 1

Vehicle Design and Safety Engineering

Transmission Construction

Measurement Engineering

Plastics and Composite Materials

Business Management 2

Quality Management

Logistics

Professional English 1
Semester 5:

Sensors and Actuators

Vehicle Dynamics

Design and $\mathrm{CaX}$

Mechanical Components

Surface Treatment

Maintenance, Recycling, Environmental Technologies and Consequences of Technology

Planning and Project Management

Professional English 2

Semester 6: (in English)

Engine and Transmission Analysis

Lab-tutorials in Electrical and Electronic Engineering

Professional Meetings

Project Work

Personnel Management, Teamwork and Communication

Automotive Specialization:

Vehicle Acoustics

Engine, Transmission and Vehicle Design

Driving Test Benches and Test Driving

Railway Specialization:

Railway Vehicle Design

Running Behaviour and Railway Vehicle Dynamics

Structural Testing and Stability Design

Semester 7:

Internship

Semester 8:

Control Engineering

Commercial and Labour Law

Project Work and Presentation

Diploma Thesis

Automotive Specialization:

Electrics and Electronics in Automotive Engineering

Marketing and Product Management (Automotive Engineering)

Railway Specialization

Railway Vehicle Acoustics

Marketing and Product Management (Railway Engineering)

Figure 1 Vehicle Technology Curriculum including specialization courses in the areas of Automotive Engineering and Railway Engineering

The $1^{\text {st }}, 2^{\text {nd }}$ and $3^{\text {rd }}$ semesters are structured in such a way as to give the students a practical foundation in the natural sciences, information technology, and a fundamental introduction to mechanical and production engineering. Machine shop practice is included in the first two semesters to supplement the theoretical lectures in mechanical and production technologies. This allows those students coming from a non-technical background to gain a greater understanding of 
the materials and processes involved in, e.g. the production of parts. English language courses also begin in the $2^{\text {nd }}$ semester.

In the $4^{\text {th }}, 5^{\text {th }}$ and $6^{\text {th }}$ semesters, students follow an interdisciplinary professional program in automotive/railway engineering. The $4^{\text {th }}$ semester contains subjects that are relevant for both specializations such as transmission design and construction as well as piston, and internal combustion engine design and construction. In the $5^{\text {th }}$ semester students finally decide on a specialization (whereby the railway specialization is only run if a minimum of five students register). Complementary subjects cover a range of topics from design through to maintenance and environmental consequences of technology. Business administration, social sciences and professional English complete the program.

In addition to lectures and lab tutorials, students work on a comprehensive project in the $6^{\text {th }}$ semester. Projects are usually selected from a range of topics supplied by industry and/or the department itself. Examples of such projects and the didactic methods employed are discussed elsewhere. There is an increasing emphasis on the development of communication and teamwork skills both in the business and language modules in the run-up to the obligatory internship.

The two final semesters represent a transition from studying to professional life. The $7^{\text {th }}$ semester is an internship semester, where students work for a minimum of 15 weeks in companies either within Austria or abroad. These internship placements are organized by the students themselves, i.e. the Department of Vehicle Engineering does not 'place' them. They do, however, have access to a database containing contact address/persons in companies working in the relevant sector of industry. These companies are typically those which have expressed an interest in having interns from our program, or where previous undergraduates have already successfully completed internships. Many students choose to do an internship in Austria or Germany, but we encourage them to travel further afield if possible. In the past we have had interns in the UK, Spain, Italy, Sweden, North and Central America, Asia, and South Africa.

The $8^{\text {th }}$ semester is a combination of taught courses and the preparation of a thesis with practical applicability. The courses cover a mixture of advanced engineering topics, business and language. The language component in the $8^{\text {th }}$ semester is specifically designed to prepare students for their final oral exam in which they present the content, methods and results of their final thesis in English.

\section{Project-Based Learning}

While project work was always foreseen as an integral part of the $6^{\text {th }}$ semester, it became apparent in the early years of the program's existence that there was a need to consider introducing it earlier. The idea to apply project-based learning (PBL) as a didactical method in the $2^{\text {nd }}$ and $3^{\text {rd }}$ semesters was primarily driven by the need to motivate the students to apply theoretical knowledge in practice as early as possible. The decision was based on the observations of staff teaching in the areas of mathematics, mechanics and information technology. They noted that students were not always enthusiastic in approaching the theoretical concepts involved in these disciplines, and that they failed to recognize the interrelatedness of what they were studying and its applicability to their future professions. These members of staff got together to define a series of projects which incorporated elements of their respective syllabi. 
They also decided to link these projects to the language courses already on offer by introducing English as the project language This project-based learning in the first and second year of the degree program is phase 1 of what has since grown into a 3-phase multi-disciplinary concept applied across the curriculum ${ }^{56}$

While the use of PBL as a didactical method is nothing new per se, it was new to our department at that point and it has allowed us to illustrate the multi-disciplinary nature not only of our program, but also of the engineering profession to our students at an early point in their studies. It motivates students to tackle difficult theoretical subjects and apply the contents to real-life problems ${ }^{5}$. The structure encourages communication, teamwork and creativity. It gives the students the chance to work through a problem autonomously, to find results and to present these results to lecturers and peers. In doing so they are developing the skills demanded by industry. The fact that, even in phase 1 of this concept, students do this in a language which is not their mother tongue gives them a further taste of what they might expect to be doing in an increasingly global workplace.

\section{Study Abroad}

Study abroad is widely considered as an essential element in helping undergraduates gain international experience. In the case of engineering students, experts argue that those with 'international study experience are more likely to be hired and prepared for the global marketplace ${ }^{5}$. With this in mind, we set about incorporating an optional semester abroad into the degree program.

While study experience abroad had been considered in the initial development phase and the search for suitable partners for student exchange began as soon as the program was up and running, it was 2004 before student mobility of this kind began.

Students opting to spend a semester abroad are required to do so in the $6^{\text {th }}$ semester of their studies. The decision to limit study abroad to this particular semester is based on the fact that, by then, students should have a strong grounding in the engineering subjects and will have at least four semesters of English behind them. As a result, they are better equipped to deal with the academic and linguistic challenges they may face at partner universities, which are either in an English-speaking country, or offer specially designed programs for international students where the working language is English.

However, not all undergraduates can be encouraged to study abroad, less so still, engineering undergraduates ${ }^{4}$.If this study abroad is optional, as in our case, it can even be problem to meet target numbers (currently 10 outgoing students per year). Thus, like many other institutions offering engineering programs, we realized that sending students abroad alone is not enough. In reality it is only one method of 'integrating international exposure into our local curriculum, 4 .

Where there are so-called 'outgoings', there should also be also 'incomings' - students who come to us from our partner universities in the UK, Mexico, Finland, Slovakia, Belgium and Bulgaria. Here too we experienced some difficulties in establishing mobility in this direction, the main obstacle being the lack of German language skills amongst potential incomings. The following section describes how we overcame these problems and succeeded in adding a further international aspect to our program. 


\section{Subject-specific lectures in English}

The introduction of subject-specific lectures taught through the medium of English is one of the more recent changes to the original curriculum in the Department of Vehicle Technology. We had been encouraged for many years by the international relations office at our university to introduce subject-specific lectures in English across the curriculum, with the aim of making our degree program more attractive to international partner institutions and to encourage student and staff mobility. Although this had been happening to a certain extent over the years, it was very much down to the initiative of a few individual members of teaching staff, and often only consisted of revision sessions at the end of a semester, or particular topics from the course syllabus which were presented in English. It was by no means enough to allow non-German speakers participate in an entire course and to obtain enough credits to meet the academic requirements of a semester abroad. In 2005, we decided to introduce English as the working language for an entire semester, both in lectures and in projects. The reasoning was twofold: firstly, as mentioned above, to encourage incoming mobility, thereby ensuring that the 'bilateral exchange' demanded by the Socrates program (now the Life Long Learning Program) program takes place. Secondly, we wanted to give students staying at home the chance to apply their language skills in a way which reflected situations they might find themselves in the workplace in future, e.g. working as part of a multinational, multicultural team, where they must be able to coordinate their work "with others who view the world through differing cultural lenses"

Introducing a semester run entirely through English is not something which can be done overnight and is certainly not without adequate preparation of academic staff. Once a general consensus to make the $6^{\text {th }}$ semester our 'English' semester had been reached by the staff (both full-time and part-time), we proceeded to address the question of how best to support this undertaking. One of the major challenges is to ascertain if the quality of the language input is adequate, i.e. do the lecturers have the necessary language skills to communicate the subject matter successfully? Management encouraged academic staff to take part in an initial screening process with the aim of providing training to improve their written and oral communication skills. Funding was provided by the Joanneum UAS, through the international office, for a residential course at Salford University in the UK, and in-house training continues to be offered at regular intervals. In addition, lecturers receive assistance from the language trainers in the department in terms of preparation and proofreading of lecture materials.

Once we announced that we were now offering an entire semester in English, the 'flow' of students from partner universities did indeed increase, so much so that in the past two years up to $25 \%$ of those participating in $6^{\text {th }}$ semester courses have been exchange students. Having a multinational, multicultural student body in the $6^{\text {th }}$ semester has some interesting effects on how the courses and projects run. The inhomogeneous nature of the groups has, for example, meant that it has been relatively easy to maintain English as a working language. Because it is the only language that all of the students have in common, they are forced to use it as a means of communication, especially in projects/teamwork. Essentially they now have to live what they were encouraged to try out in projects in earlier semesters in terms of using English as their project language. Another interesting effect can be seen in language and communication courses (e.g. in Professional Meetings or Personnel Management, Teamwork and Communications), where elements of cross-cultural communication, which previously had to be taught in a somewhat artificial way, can now be experienced directly within the classroom. 


\section{Formula Student Project}

One of the major projects in the $6^{\text {th }}$ semester is Formula Student, the SAE $®$ international competition for undergraduate students of mechanical engineering disciplines. This competition provides the students with a real-life exercise in design and manufacture, and encourages them to consider the business elements of automotive engineering as an integral part of their technical considerations. It teaches them about team working, under pressure and to tight timescales ${ }^{8}$.

Because the competition attracts entries from universities all over the world, it is an excellent opportunity for students not only to meet with and compete against international teams, but also to compare their education and skills to those of their counterparts around the globe. For us, as for other universities, Formula Student represents a valuable project that 'blends academic work and learning with the development of practical engineering skills, ${ }^{8}$ in a way that is both motivating and rewarding for the participants. It is also gives them an excellent insight in to what it means to be a 'global engineer' in every sense of the word.

Our experience over the past four years has shown us that the motivation amongst our students to participate in this international project is high. This motivation appears to trickle down to the lower semesters also, where the successes of the teams have generated considerable interest among the 'younger' students' in e.g. any Formula Student related 'sub-projects', such as the development of software tools for optimizing the performance of the racing car as part of $3^{\text {rd }}$ semester projects ${ }^{9}$.

\section{Conclusion}

Many of the measures presented in this paper have only been in place for a short time, so it is difficult to assess at this stage what the long-term impact on the program and its graduates will be. Initial feedback is promising. We are acutely aware, however, that we have a long way to go. The next stage should almost certainly be to carry out some form of systematic evaluation of the use of English as a working language in the $6^{\text {th }}$ semester to identify possible areas for improvement. We should then take a look at how we might be able to incorporate further intercultural training to complement the language training for both staff and students in preparation for the $6^{\text {th }}$ semester, for example.

The curriculum is due to undergo a major revision in the coming two years to mark the changeover from a four-year undergraduate degree program to the Bachelor/Masters system outlined in the Bolonga Agreement. This will be an ideal opportunity to revise the contents and structure of the program to further pursue our aim of providing international exposure for all of our graduates.

Neither the industry in which the graduates of Vehicle Technology aim to work, nor the academic institutions in which they are educated are static entities. Therefore, as educators we must continue to examine what we do and how we do it to ensure that our students gain the right mix of knowledge and skills, and hence ensure them a place in the global market. 


\section{Bibliography}

1. E Leitner (2004), 'Die österreichische Fachhochschulen: Entwicklung u. Strukturen eines marktorientierten Hochschulsektors, 15 Jan. 2008, http://www.ihf.bayern.de/dateien/beitraege/Beitr_Hochschulf_4_2004.pdf

2. http://www.fh-joanneum.at

3. P Crowther, M Joris, M Otten, B Nilsson, H Teekens, B Wächter (2000), "Internationalisation at home -a position paper." European Association for International Education (EAIA), p.10.

4. E Doerry, K Doerry, B Bero (2004).'The Global Engineering College: Lessons Learned in Exploring a New Model for International Engineering Education,. Proceedings of the 2004 American Society for Engineering Education, Annual Conference \& Exposition.

5. G. Bischof, E. Bratschitsch, A. Casey, and D. Rubeša (2007), 3-Phase Multi Subject Project Based Learning as a Didactical Method in Automotive Engineering Studies, Proceedings of the 2007 American Society for Engineering Education, Annual Conference \& Exposition.

6. G. Bischof, E. Bratschitsch, A. Casey, and D. Rubeša (2007), Facilitating Engineering Mathematics Education by Multidisciplinary Projects, Proceedings of the 2007 American Society for Engineering Education, Annual Conference \& Exposition.

7. National Resource Centre on Engineering Education (1998-2006), University of Rhode Island, 11 Oct. 2007, http://www.uri.edu/iep/nrc/rationale.htm

8. Formula Student 2008 (2007), Institution of Mechanical Engineers, 15 Dec 2007, http://www.formulastudent.com/.

9. http://www.joanneum-racing.at

10. R Echempati, M Butsch (2007). "Mechanical Engineering Study Abroad program in Germany Experiences and Lessons Learned", Proceedings of the 2007 American Society for Engineering Education, Annual Conference \& Exposition.

11. Graduate Employability Skills (2007), Precision Consultancy, Dec.1 2007,www.dest.gov.au/../E58EFDBEBA83-430E-A541-2E91BCB59DF1/18858/GraduateEmployabilitySkillsFINALREPORT.pdf

12. From: Globalization and higher education: eight common perceptions (2007), Van R. Wood, 11 Oct. 2007, http://www.iienetwork.org/page/84658/

13. E. W. Johson, S. Glenn DeMaris, Online Journal For Global Engineering Education (2007), Vol. 2, Issue 1, Developing an International Engineering Experience for Undergraduate Students at a Small Institution", The Berkley Electronic press. 9 Oct. 2007, http://digitalcommons.uri.edu/ojgee

14. I. Hack, C. Boje (2006), How do we provide an International Experience for Undergraduate Technology Students at Regional Campuses?, Proceedings of the 2006 American Society for Engineering Education, Annual Conference \& Exposition 